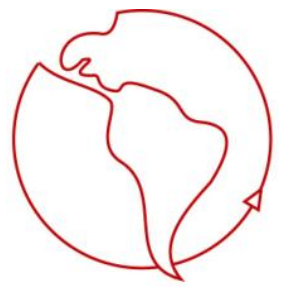

\title{
El Ramu en Meré: Etnografía de una Fiesta Religiosa al Norte de España
}

Ester Massó Guijarro

Departamento de Filosofía, Universidad de Granada, España

lagodesal@yahoo.es

\section{Resumen}

Voy a exponer los resultados obtenidos de un breve estudio etnográfico ${ }^{1}$ realizado en Meré, localidad perteneciente al ayuntamiento de Llanes en el valle de Ardisana (Asturias, España). La exploración etnográfica se ha llevado a cabo, en su totalidad, en el plazo de una semana, por lo que he debido centrarme (en aras de alguna precisión) en un tópico cultural concreto del ámbito de desarrollo del trabajo; así, me he dedicado principalmente al estudio de la fiesta local anual denominada "la Sacramental" o "el Ramu", celebrada normalmente en torno al primer fin de semana de julio y coincidente, pues, con mi estancia en Meré.

Daré cuenta aquí de las funciones clave y el desarrollo pormenorizado de la celebración (descripción densa en el sentido de Geertz), si bien no dejaré de comentar algunos otros aspectos cruciales de la cultura lugareña con los que me he topado. Sirva esta sucinta aproximación como posible primera piedra de algún estudio posterior de mayor envergadura.

La metodología empleada ha sido la observación participante, la realización de entrevistas abiertas y semidirigidas a distintos informantes, las charlas espontáneas y la consulta bibliográfica de documentos que reseñaré en el lugar correspondiente.

Palabras claves: etnografía, fiesta, simbolismo, religión, funcionalismo.

\section{Introducción y Comentario sobre la Revisión Teórica}

En el estudio que tienen en sus manos se presentan los resultados obtenidos de una breve etnografía de una semana de duración, realizada en el municipio de Meré perteneciente al ayuntamiento de Llanes localidad costera del oriente de Asturias.

Se centra el texto en una aproximación pormenorizada a la fiesta anual llamada "la Sacramental" o "Ramu", que suele celebrarse a principios de julio y coincidió con mi estancia de observación en el campo. Así, si bien han sido multitud los aspectos interesantes estudiados y recogidos durante este período, centramos la brevísima monografía en el tópico de la fiesta.

La delimitación del objeto de estudio no ha sido sencilla, pues; no sólo mi desconocimiento previo del terreno la dificultó en un primer momento sino que, paradójicamente, tras mi llegada fue el diluvio de información que aconteció el que obstaculizó mi intención de centrar el trabajo en un solo tema.

Mi estancia de trabajo surgió a raíz de la una Escuela veraniega de Antropología, la celebrada anualmente en Santander y coordinada por el maestro Lisón Tolosana; así, el interés no estriba sólo en los resultados

\footnotetext{
${ }^{1}$ Esta estancia se realizó con motivada por la Escuela de Antropología Social "Julio Caro Baroja", celebrada durante julio de 2004 en Santander, España, bajo del dirección de don Carmelo Lisón Tolosana y la tutorización del profesor don Eloy Gómez Pellón.
} 
etnográficos obtenidos concretos sino en la experiencia misma de la convivencia antropológica, como trataré de mostrar aquí deteniéndome con lentitud, a veces, en los pormenores metodológicos.

Algunos aspectos observados, tremendamente relevantes a mi juicio desde un punto de vista antropológico, habrán de quedarse guardados en mi cuaderno esperando, tal vez, un futuro tratamiento; aspectos como el tipo de identidad cultural y de cohesión grupal existente en el lugar, o el conflictivo choque entre la economía tradicional (una economía incrustada, siguiendo la noción de Polanyi, y no regularizada) y los imperativos e intransigencias de la economía global regularizada (un caso muy similar, en algunos aspectos, al problema asociado a los derechos de la tierra en África, por ejemplo), las peculiaridades del habla local (que muestran, a mi entender, su ligazón con el catalán, el gallego y el portugués), la proliferación del turismo rural, la paradoja (vista como tal entre las gentes oriundas) entre una cuestionable defensa del bable y la destrucción que están suponiendo para el modo de vida tradicional las medidas ecológicas y económicas adoptadas por el gobierno; la porosa interacción entre las juntas vecinales y los ayuntamientos, o incluso temas como las modificaciones en las relaciones de parentesco o las pautas de cortejo y elección de pareja, constituyen todos ellos tópicos culturales interesantísimos que por su amplitud no puedo tratar debidamente en este ensayo.

Sobre la revisión teórica, primeramente debo decir que el material recibido en la Escuela de Antropología Social "Julio Caro Baroja" mencionada, en el seminario llamado "Trabajo de campo: métodos y técnicas" celebrado durante la semana previa al desarrollo de mi estudio ha constituido, en su totalidad, una herramienta de inestimable utilidad para éste. Huelga tal vez citar de modo regular en la bibliografía a la profesora Ana María Rivas y a los profesores Eloy Gómez Pellón y Carmelo Lisón Tolosana ya que opino que, más bien, merecen en este lugar una mención diferente; todas sus comunicaciones de estos días anteriores me han servido como fondo teórico de reserva clave a la hora de enfrentar mi experiencia de campo.

Mi desconocimiento absoluto inicial del terreno, como dije, me inhabilitaba para plantear unas hipótesis de trabajo iniciales previas que resultaran sólidas y atinadas; así, me he visto prácticamente "abocada" al estudio de la fiesta del Ramu, ya que casualmente se celebraba al día siguiente de la noche de mi llegada y constituye, de hecho, un tópico cultural y ritual crucial en Meré. Resulta obvio, pues, que he debido llevar a cabo una discriminación temática en mi estudio.

De esta cortedad inicial en mi acervo de conocimientos sobre la región, así como de la cortedad misma del tiempo de investigación en el terreno se derivan la ausencia casi total de revisión teórica previa (fundamental, creo, en cualquier trabajo convincente) y la de un epígrafe acerca de mis hipótesis iniciales de trabajo (también ineludible para la claridad y la honestidad del/a investigador/a). Puedo afirmar, así, que ésta ha constituido una aproximación partisana a un estudio etnográfico; he ido modelando mis intereses, planteamientos y miradas desde el primer momento en que llegué, y el torrente informativo y vivencial que constituye cualquier cultura local comenzó a apoderarse de mí.

Antes de dar por finalizada esta introducción y pasar al siguiente epígrafe, deseo realizar la parte más importante de esta memoria: los agradecimientos. Debo dar las gracias de todo corazón a varias personas: al profesor Eloy Gómez Pellón por actuar de intermediario entre la familia con la que he vivido y yo misma; y a las gentes de Meré, sin excepción, por su hospitalidad extrema, su amabilidad, su calor y su ingente calidad humana. Así, doy gracias a Elena, a María y a Constante, al güelo Severiano, a Celi y a José María, a la Nena, a Joaquín y a Quili, y cómo no, a los pequeños Sergio e Irene que tanto me han alegrado y enseñado; y a todos y todas los que falten aquí por citar (muchos y muchas, sin duda) y que me han ayudado a vivir y aprender en el valle de Ardisana. Sin todos ellos y ellas, nada de esto hubiera existido. 


\section{Práctica Metodológica}

Las técnicas de recogida de datos que he empleado han sido las siguientes:

Observación participante, realizada desde el primer instante ya que he tenido el privilegio de convivir durante toda la estancia de campo con una familia lugareña que ha operado, además, de intermediaria constante entre el espacio humano y yo misma. La hija pequeña de la familia, de una edad muy próxima a la mía, ha constituido tal vez mi informante clave, ya que ha pasado conmigo casi la totalidad del tiempo hablándome, instruyéndome, respondiendo a mis preguntas y mostrándome cada lugar, cada refrán, cada tradición.

Resulta inestimable la estancia en el campo para llegar a asimilar ciertas realidades, a percibir ciertas otras, a comprender todas ellas como un conjunto en un ordenado holismo. La observación participante permite a la persona contrastar los discursos orales con otro tipo de discursos (los conductuales, por ejemplo); si bien el discurso oral constituye en sí un tipo de acto (no menos tangible, a mi entender, que otros, en tanto que hablar es ya una actitud), sí resulta útil para llegar a penetrar en una realidad asumir cómo aquel discurso se articula con "lo que se hace", cómo se enraíza en ello o bien disiente, se desmarca adquiriendo un rostro diferente.

Los espacios físico-simbólicos y de interacción observados más importantes han sido los siguientes: el espacio doméstico (la casa más otras unidades de la misma como el lagar, el garaje, el "hórriu" con la cosecha, los quesos y los "gochus" debajo, el corral con patos, gallinas y pavos, y el "prau" con sus vacas y el caballo de tiro), el pueblo de Meré (sus calles, sus tres bares -uno de ellos con tiendecilla-, su pequeña iglesia y sus nada menos que cinco alojamientos de turismo rural), el mercado (en Cangas de Onís; fuimos el domingo 11 de julio de 2004 y pude observar entre otras cosas cómo compraban unas aves en uno de los puestos), el pueblo de Llanes (donde visité y consulté en la oficina de turismo y en la biblioteca, sita en la Casa de la Cultura), un molino de familiares cercanos (donde, con suma amabilidad, se me mostró el funcionamiento así como otras producciones como un lagar de sidra y un taller de madera), algunos pueblos aledaños (como Porrúa, donde visitamos el Museo Etnográfico del Oriente de Asturias, que lleva funcionando desde el año 2000), mi visita al valle de Ardisana (guiada gentilmente por una lugareña, que estuvo andando conmigo durante unas cinco horas y hablándome sobre todo tipo de cuestiones relacionadas con la zona) y, el más relevante, el espacio físico y simbólico crucial para mi trabajo: la fiesta de la Sacramental, el Ramu celebrado en Meré el día 10 de julio, sábado, del que realizaré una descripción densa en el epígrafe destinado a resultados.

Conversaciones espontáneas-abiertas, que han significado, junto con la observación participante (y siendo parte de ella en realidad) la técnica más interesante e informativa. Sin duda, como mejor se aprehende una cultura o una situación no es forzando la circunstancia artificial de una entrevista (ya sea más o menos estructurada) sino provocando el diálogo en una con-versación (que, a fin de cuentas, no significa más que "hacer el verbo común").

Así, las charlas espontáneas tanto en el ámbito doméstico (con el abuelo, con los niños, durante las comidas) cuanto en el exterior (con las mismas personas o distintas como, por ejemplo, una conversación mantenida con un habitante de Niembro que asumió durante cuatro años la alcaldía pedánea de esta localidad por el PSOE, y que me informó de cómo interactúan las juntas vecinales hoy con los ayuntamientos) han resultado un cauce informativo crucial. La visita al mercado de Cangas de Onís (donde, sobre el terreno, uno de los informantes mayores me iba explicando pormenores de los puestos y comercios), las conversaciones con diferentes personas durante el ritual de la fiesta (amigos/as, familiares 
de mi familia de acogida, etc.), comentarios en tiendas, establecimientos o incluso por la calle, todo ello ha servido como fuente fundamental de datos. Al fin y al cabo los agentes culturales de cada cultura, los "expertos" de la misma, la aprenden de ese modo; y si bien nosotros los y las antropólogas hemos ciertamente de forzar y aligerar las situaciones de aprendizaje e interacción -dada nuestra condición no nativa y las limitaciones temporales-, no tengo dudas sobre cuál es la mejor vía para hacer etnografía: la fluidez corriente de la vida normal (o, como diría Juan de Mairena sobre "los eventos consuetudinarios que acontecen en la rúe", lo que pasa en la calle).

Entrevistas semiestructuradas, empleadas casi en exclusiva en situaciones donde el encuentro personal no ha sido espontáneo. La más representativa ha sido la llevada a cabo con el informante llamado don Fernando, dueño de la casa de Meré que los lugareños denominan "el Palacio" (se desarrolló en torno a las 15.30 horas del día 13 de julio, después de la comida y en casa del propio informante. Estuvimos charlando en torno a una hora y, si bien la entrevista resultó enormemente interesante desde varios puntos de vista, fue poco informativa sobre el tema concreto de la fiesta y el Ramu).

Debo reseñar un aspecto importante sobre el registro de las entrevistas; si bien mi idea inicial era realizarlo mediante una grabadora (con la subsiguiente transcripción y análisis cualitativo del discurso), me topé con la eventualidad de que mi aparato de averió (tampoco pudieron prestarme ningún magnetófono).

Sin embargo pienso que esto ha resultado finalmente un problema menor. He podido mantener conversaciones más o menos abiertas y/o guiadas casi durante todas las horas en que he estado despierta con personas diversas, escuchando perspectivas y miradas diferentes (edades, situaciones, estados de ánimo...). Mi memoria a corto plazo y la posibilidad de volver a consultar con los propios actores sociales de forma recurrente ha suplido, a mi entender, cualquier deficiencia de registro.

Incluso sobre las peculiaridades del habla local he tenido oportunidad de realizar una breve reflexión a pesar de no contar con transcripciones directas de entrevistas; de nuevo, el hecho de convivir a diario con estas personas me permite escuchar constantemente su forma de hablar y tenerla lo suficientemente próxima como para poder pensar sobre ella.

Revisión bibliográfica y hemerográfica, de la que daré cuenta en la bibliografía. Todo el contenido hemerográfico consultado, así como otro tipo de documentos intermedios también reseñados más adelante, me han sido facilitados por la propia familia de Meré con la que he convivido. La información que me han aportado ha resultado más bien genérica sobre la región, aunque he encontrado algunas referencias muy útiles sobre la misma fiesta del Ramu.

Empleo de recursos visuales técnicos (toma de fotografías), especialmente de la fiesta del Ramu en cada uno de sus momentos y de algunos espacios considerados importantes durante nuestra estancia en el campo: el mercado, la iglesia de Meré, etc. La calidad de las fotografías no es muy buena, debido tanto a mi mal hacer como fotógrafa cuanto a la misma cámara empleada (de usar y tirar); tómense pues sólo como una pequeña muestra informativa más ${ }^{2}$.

\section{Presentación del Ramu. Contextualización y algunas generalidades.}

\footnotetext{
${ }^{2}$ No podemos incluir en los apéndices documentales las fotografías ni algunos otros documentos lugareños obtenidos, ya que quedaron guardados en la Escuela de Antropología de la Universidad Internacional Menéndez Pelayo.
} 
La fiesta llamada "la Sacramental" o Ramu se lleva celebrando en toda la zona llanisca (perteneciente a Llanes) desde tiempos inmemoriales, como aseguran los lugareños. No podemos ofrecer una fecha exacta de origen porque ninguna de las personas a las que pregunté, incluso las más ancianas, lo recuerdan.

Mi estudio se centra en la celebración del Ramu en Meré, pequeña localidad perteneciente a Llanes que, en estos momentos cuenta con una población de menos de un centenar de habitantes (tal vez se aproxime más a la cincuentena, incluyendo en el cómputo al llamado "barrio del Cuetu"). Según sus habitantes hace algunas décadas Meré contaba con una población mayor, pero ha experimentado un proceso de recesión demográfica con un esquema análogo al de tantas otras localidades: envejecimiento de la población, caída de la natalidad a causa de la emigración laboral y notable pérdida de efectivos.

Estos avatares demográficos y económicos no dejan de afectar, naturalmente, a la misma fiesta local. El hecho de que haya menos jóvenes, mozus y mozas, que puedan participar del Ramu condiciona su forma de ser y desarrollarse. Pero vayamos por partes.

"La Sacramental" recibe ese nombre porque el centro religioso de la fiesta, la piedra angular, la constituye el Corpus Christi -nombre que recibe una fiesta católica fundamental, celebrada en fechas distintas en muchos otros lugares-. El nombre alternativo, Ramu, hace referencia a otro elemento clave del evento, precisamente el objeto ritual que se ofrece a la divinidad y que consiste en una armadura cónica de madera en la que se enganchan panes en forma de rueda, adornados con grandes hortensias de distintos colores. Este Ramu, de aproximadamente un metro de altura, es anualmente "ofrecido" por una familia o una persona (en agradecimiento a algún don recibido de la divinidad o bien en petición de algún otro), que se encargan de pagarlo y desde cuya casa se iniciará la procesión.

Pero el Ramu comienza antes de estos momentos; el Ramu comienza cuando, tiempo antes, alguna persona o personas se encargan de movilizar a la población local para que "haya Ramu", es decir, para organizar el evento. Esta persona o personas activan redes de relaciones sociales, convocan una comisión de fiestas que recaude fondos, animan y estimulan; el rol que desempeñan es fundamental porque sin ellos el Ramu no sería posible y, de hecho, no todos los años lo hay. Cuando preguntaba por qué no lo ha habido en años anteriores, me contestaban indefectiblemente que "porque nadie se había movido" para ello.

Por otro lado, los agentes que estimulan a la comunidad no tienen por qué ser necesariamente los que paguen el Ramu, es decir, los que se encargan, como indicamos más arriba, de costear los panes y flores que lo componen y quienes, por ende, lo ofrecen al santo Sacramento por diversos motivos.

Así pues nos hallamos ya con, al menos, dos agentes fundamentales en el evento del Ramu: la persona o personas que movilizan a la comunidad para que formen comisión de fiestas, y la persona o personas (familias) que lo pagan y ofrecen.

Existen otros personajes relevantes que operan en distintas esferas, como la moza (chica o mujer) que toca el tambor. Durante la procesión del Ramu todo el conjunto de mozas vestidas de aldeanas (el traje tradicional llanisco) toca una pandereta adornada con cintas de distintos colores, pero solamente una de ellas marca el ritmo con un tambor; no resulta baladí, desde luego, quién lo hace. Habitualmente es la misma persona durante cierto tiempo (hasta que cambia algún año, por algún motivo concreto) ya que debe saber tocarlo; además, suele ser una mujer especialmente interesada e implicada en la fiesta y que, además, coordina los ensayos para el desfile y ordena a las otras mujeres (sobre todo a las niñas), inicia los cantos $y$, de forma palpable, ocupa un lugar preponderante en el evento. 
Otro personaje fundamental del Ramu, desde el punto de vista religioso, es el sacerdote que oficia la misa y porta el Santo Cuerpo durante la procesión; su figura, intercambiable a nivel personal (es decir, no importa quién sea la persona sino el rol que desempeña), posee un valor ritual clave que comentaremos en otro momento.

\section{Descripción densa del Ramu: 10 de Julio de 2004 en Meré de Llanes}

Para mí la fiesta del Ramu en Meré comenzó la noche de la víspera, en que llegué a la casa de la familia que me ha acogido aquí y pude percibir de forma bien tangible la emoción y la expectación reinante en todos los miembros de la familia pero, en especial y con diferencia, en las mujeres que iban a vestirse de aldeanas: dos mujeres jóvenes, hermanas, con algunos años de diferencia, y una niña pequeña (la hija de la mayor). Se acuestan hablando sobre la celebración de la mañana, completamente nueva para mí, y que iba a inaugurarse con el acto de "ir a vestirse y peinarse" por la mañana.

El día del Ramu amanece temprano, incluso para los niños y las niñas más pequeños. Ya hay actividad en la casa sobre las ocho de la mañana y pronto, en torno a las nueve y media, las mujeres y las niñas comienzan a acudir a la antigua escuela de Meré (ahora en desuso, ya que los pequeños eran tan escasos que se cerró y los trasladaron a otro pueblo cercano mayor). Allí nos encontramos con mujeres de todas las edades, no sólo habitantes de Meré sino de pueblos cercanos -la mayoría nacidas en Meré pero residentes en otros lugares por motivos de trabajo, familia u otros. Una de las razones por las que se continúa celebrando el Ramu en verano es, según los informantes, porque puede venir más gente de otros sitios, gentes ligadas de algún modo a Meré pero que (ya) no viven allí. Así, muchas de las aldeanas se desplazan de otros pueblos.

Casi todas ellas, salvo dos o tres que poseen traje propio (una de ellas la chica del tambor, hija de la alcaldesa pedánea de Meré y ducha gaitera, según cuentan) o a las que se lo han prestado, han alquilado su traje por unos setenta y cinco euros en Llanes, en una casa especializada. Por la mañana llevan todos los trajes desde Llanes hasta Meré, y dos mujeres empleadas de dicha casa acuden a la vieja escuela para ayudar a las mujeres a vestirse y para peinarlas y colocarles el pañuelo, difíciles tareas en las que ellas son expertas.

Colocarse el traje de aldeana y peinarse con el pañuelo picado no son tareas fáciles; téngase en cuenta que durante todo el día la mayoría de estas mujeres van a mantener el traje y el tocado y no se lo quitarán hasta la noche, que suele prolongarse mucho. Así, las telas han de anclarse bien a base de alfileres estratégicamente situados, tanto como el pañuelo y el cabello mismo.

Llegamos, pues, a la escuela, y un ilusionado bullicio fluye a borbotones. Niñas muy pequeñas paseándose entre los trajes, a medias de vestir y jugando con el vuelo de las amplias faldas; mujeres charlando, intercambiando impresiones sobre la celebración de este año y de años anteriores. Algunas de las niñas no saben hablar casi, tienen apenas dos años, alguna tres, pero ya muestran un inusitado interés por vestirse y peinarse como "las mayores". Algunas niñas un poco mayores y las adolescentes estimulan y alimentan este empeño con comentarios y risas.

Algunas pequeñas se quejan sobre el pañuelo, que aprieta al principio (ya hemos dicho que debe de estar muy bien sujeto para aguantar más de doce horas en su lugar), pero las mujeres consuelan estos llantos apelando a "lo guapas que van a ir" y a lo bonito que es salir de aldeana. Claramente, la socialización actúa; escucho muy a menudo que a las pequeñas "les luce más". 
En el centro de esta sala aguarda el Ramu, el objeto descrito más arriba (ya pertrechado con sus panes y flores) y que más tarde será clave de la procesión.

Así, las féminas van vistiéndose y peinándose, con más o menos ayuda de las encargadas y apoyándose unas a otras en este proceso. Todas son conocidas; algunas niñas muy pequeñas son ayudadas a vestirse por otras mujeres que no son sus madres. Se palpa la alegría de compartir una fiesta, y la expectación.

Cuando las personas con las que voy están listas, salimos de la escuela. El siguiente paso comunitario de la fiesta comenzará sobre las doce con la procesión, pero ya antes suenan una gaita y un tambor que bajan por el camino y hacen altos en algunas casas, donde tocan y son convidados a un poco de sidra o licor de guindas.

Cerca de las doce ya hallamos congregada a gran parte de la comunidad, ataviada con sus mejores galas, en la puerta de la familia que ofrece el Ramu donde éste aguarda a ser alzado por cuatro mozus del pueblo; las mujeres y niñas vestidas de aldeanas (cerca de treinta), los escasos niños vestidos de porruanos (traje que, por su sencillez en la colocación, se viste en casa sin ningún problema, aunque es también traído desde la misma empresa de Llanes), ya pertrechadas ellas con sus panderetas y tambor y ellos con sus palus, se van colocando en filas de cuatro y por orden de altura (las más altas detrás), ellos delante y ellas después. Preside la comitiva el Ramu y se disponen a comenzar la procesión, suceso que guardará el esquema generalizado ${ }^{3}$ de la zona "procesión-misa-procesión".

Comienzan a sonar las panderetas, marcando el ritmo el tambor. Los mozos levantan el Ramu. Suenan las voces de las mujeres, entonando una letra de obertura de la ceremonia con una melodía que se repetirá en todas las canciones. Cuando terminan de cantar, y marcando un ritmo distinto con la pandereta (se emplean dos: uno para los cantos, otro para el paso), toda la comitiva echa a andar.

Suenan petardos. La persona que va lanzándolos es el hombre que, según me cuentan, ha organizado el Ramu movilizando a la comunidad y logrando que se formara la comisión de fiestas; lo hizo también en años anteriores. Durante toda la procesión este hombre irá delante de la comitiva, siempre el primero, lanzando los cohetes. Asimismo, será él quién subaste el Ramu tras la procesión, y también figurará en el escenario con la orquesta durante la noche, coordinando el concurso de baile e incluso cantando. Su papel resulta de sumo interés antropológico, y será comentado más adelante.

La procesión se dirige a la pequeña y hermosa iglesia del pueblo, en cuya puerta entonan otro canto oferente acorde con la situación. Las gentes van entrando y las aldeanas se ubican en torno al altar, rodeándolo junto a la pared.

La misa no resulta demasiado larga y el sermón del cura se orienta claramente al fortalecimiento de las redes familiares y vecinales, incidiendo en la importancia de la armonía y la generosidad en la convivencia, la conveniencia de olvidar rencillas y procurar la unión popular. Resulta obvio que todos éstos son valores imprescindibles para la vida de estos lugares, nunca sencilla.

Se finaliza la ceremonia religiosa con otro canto de las aldeanas y se prosigue la procesión, ahora con un palio sostenido por cuatro feligreses voluntarios y bajo el que el sacerdote, ataviado con ropaje ritual, porta la Santa Figura elevándola con los brazos.

\footnotetext{
${ }^{3}$ Del Campo Santos, 1997: 162,
} 
La configuración de la procesión es ahora la siguiente: a la cabeza nos hallamos con el hombre de los cohetes, mencionado más arriba; después los niños vestidos de porruanos en fila de tres, portando el del centro una pequeña cruz y los dos que lo flanquean sendos velones; luego el gaitero y el tamborilero tocando, seguidos del Ramu; más atrás, el palio; las aldeanas tocando tambor y panderetas y por último, cerrando la comitiva, las gentes del pueblo (la disposición, como se ve, no deja de presentar cierta complejidad).

Esta segunda fase de la procesión realiza dos altos en el camino; el primero, en un pequeño altar preparado en una de las calles del pueblo; el segundo, en el patio de la casa que llaman "el palacio" (perteneciente a una familia rica e influyente; véase apéndice 1). Ambas paradas están destinadas a la lectura de textos religiosos, a modo de plegarias y ofrecimientos ${ }^{4}$.

La procesión termina de nuevo en la puerta de la iglesia, donde las aldeanas entonan el último canto de cierre colocadas en círculo.

Tras finalizar la ceremonia, se da paso a la subasta del Ramu y se entrega un bollo a todos los participantes de la procesión. Lo que se subasta en concreto son los panes del armazón junto con la flor que adorna cada uno más otro pan que se extrae de una caja aparte; se obtiene en la puja de cada pan entre 10 y 20 euros, aproximadamente, y las ganancias se destinan al pago de la fiesta.

Ya son casi las tres de la tarde y la gente marcha a comer a sus casas. El Ramu ha congregado familias, visitantes que sólo acuden a Meré en días de fiesta, padrinos y amigos lejanos. Se prepara viandas variadas, sidra y licores, tartas para los postres. Como en toda celebración, la comida y la bebida compartidas ocupan un lugar clave.

No se volverá a reunir toda la comunidad hasta la noche, en torno a las nueve o las diez, cuando la plaza comienza de nuevo a cobrar vida, la orquesta empieza a tocar, los bares sirven copas y bebidas varias y los niños disfrutan en el puesto de golosinas y juguetes. La fiesta se prolonga hasta la madrugada; se organiza un concurso de baile en el que participan hombres y mujeres, grandes y pequeños; las gentes de pueblos cercanos acuden para participar de la diversión en Meré. Muchas mujeres siguen vestidas de aldeanas, conservando osadamente su hermoso tocado.

El domingo, cansancio y añoranza por la fiesta terminada. "Me da pena quitarme el traje", me decía una de las informantes, aún agotada de todo el día a altas horas de la madrugada. "Hasta el año que viene...".

El lunes a las 12 de la mañana regresaron de Llanes a recoger los trajes de aldeanas y porruanos en una furgoneta, en la puerta de la escuela donde se vistieron. Se pagó los alquileres durante la recogida.

\section{Aldeanas y porruanos: los trajes}

\footnotetext{
${ }^{4}$ Esta cuestión me ha parecido interesante, aunque tal vez resulte arriesgada una conclusión sobre ella. Nótese que el alto se hace en dos lugares concretos: una calle, es decir un espacio popular por antonomasia, y el patio del "palacio", espacio privilegiado y particular a su vez, la "casa del rico" dicho de otro modo. Además escuché en una conversación que en alguna ocasión el dueño del "palacio" había pagado para que se hiciera allí la parada, o bien que después de ella había hecho alguna donación a la iglesia (es un hombre muy piadoso). Creo que esto puede ser significativo, ¿tal vez de la unión entre distintas clases -casi estamentos- mediante la religión? Como digo, se antoja excesiva una conclusión así, pero da qué pensar.
} 
Los trajes tradicionales llaniscos (del municipio de Llanes) que son usados en Meré se llaman "de aldeana" (el de la mujer) y "de porruano" (el del hombre; hemos de decir que Porrúa es el nombre uno de los pueblos cercanos). El traje de aldeana se compone de faldón, camisa, chaleco, falda, mandil, banda, solitaria (antes dengue o rebocillo), chaqueta (que se usa sólo colgada del hombro), pañuelo y por último, como tocado, un par de claveles prendido sobre una rama de espárrago en el hombro izquierdo (sobre la chaqueta; en cada uno de los pueblos de Llanes la flor se emplea para distinguir: el clavel es propio de Meré).

El elemento más destacado de la indumentaria femenina lo constituye sin duda el coral, que adorna todas las piezas visibles y confiere al traje no sólo un considerable peso (en torno a unos siete kilos) sino, especialmente, un rasgo de prestigio. El traje de aldeana es realmente oneroso; mis informantes estimaban su precio de compra en torno a un millón de pesetas antiguo, y su alquiler cuesta en torno a setenta y cinco euros. Es obvio para ellas que resulta caro pagar ese precio por lucir un día, pero también resulta de una aplastante trivialidad que lo pagarán, mientras puedan hacerlo.

El traje de aldeana, por otro lado, suele combinar dos colores (además del negro): rosa y gris, azul marino y cobre oscuro, rojo y negro, granate y negro, etc. Es habitual que se complete el tocado con pendientes y collares, tradicionalmente de coral rojo (o imitación del mismo). Los zapatos son negros, con más o menos tacón, y planos con calcetines para las niñas.

El traje de porruano nunca ha sido tan caro (ni desde luego tan pesado), según las informantes. Lo componen los escarpinos, corizas, medias (de lana hasta la rodilla), calzón y pantalón, camisa y chaleco, fajín y la montera picada. El tocado final se complementa con un "palu", una especie de bastón de madera bastante retorcido que llevan en la mano. La combinación cromática suele ser también bicolor: negro y marrón, o azul oscuro, o granate...

Las distintas perspectivas de género se dejan notar aquí, como en tantas otras cuestiones; son las chicas, las mozas y mujeres las que se visten de aldeanas en mucho mayor número que los mozos. Según me contaron, en épocas más antiguas se vestían algo más, y también hoy hay más porruanos en pueblos distintos de Meré. Pero nuestra experiencia observada en esta localidad resultó aplastante: cerca de treinta mozas vestidas de aldeanas (entre niñas muy pequeñas, adolescentes, mujeres jóvenes e incluso mujeres maduras), frente a cuatro o cinco niños pequeños vestidos de porruanos. Y ningún hombre adulto.

\section{Evolución y Transformaciones del Ramu}

A pesar de mi insistente indagación acerca de los posibles cambios y transformaciones experimentados por la fiesta del Ramu a lo largo de las últimas décadas, las respuestas de mis informantes (algunos/as mayores, con el fin de lograr una verdadera perspectiva diacrónica) eran unánimes: en lo esencial no ha cambiado nada. Solamente pudimos registrar algunos aspectos de cambio como la introducción de la orquesta para la fiesta nocturna, frente a la antigua música de gaita, tambor y violín que sonaba en el centro de la plaza animando a la comunidad. También era común que, en consonancia con este tipo de música, las gentes entonaran distintas coplillas inventadas recordando sucesos y personas de la comunidad, casi todas cómicas 5 .

Asimismo, se me informó de que hace algunas décadas era mucho más común que las casas tuvieran al menos un traje de aldeana ya que lo confeccionaban las propias mujeres, funcionando en mucha menor

${ }^{5}$ Recogimos algunas tales como: "Quien entró en pueblo de Piedra/ que le robó el puchero a Rita/ y el pobre titiritiri/ se quedó sin la fabita", o "A una moza celoriana/ Quinto le rompió los huevos". 
medida el alquiler. Los trajes resultaban entonces más humildes, con menos coral (sólo en el dengue o solitaria), empleándose como elemento ornamental especialmente el terciopelo.

También parece haber cambiado algún elemento de índole más ritual, como el hecho de que tres o cuatro décadas atrás las aldeanas no podían entrar al altar, como sí hacen ahora. Sin embargo, a excepción de los aspectos mencionados, los informantes afirmaban que todo funcionaba antes de forma similar, tanto el desarrollo de la fiesta en sí como sus preliminares (movilización de la población, ofrecimiento del Ramo, la chica del tambor, etc.).

\section{Discusión y Conclusiones}

Muchos de los datos recogidos pueden ser contrastados en varios lugares de la bibliografía existente; todas las cuestiones referentes a la indumentaria aldeana (la flor del bando, el picado del pañuelo) y a la celebración ritual del Ramu (el esquema procesional, la mixtura de elementos profanos y religiosos), entre otras, han sido ya ampliamente registradas por Teresa del Campo Santos, Eloy Gómez Pellón y/o distintos grupos de investigación de la Comunidad de Asturias ${ }^{6}$.

Resulta obvio que mi trabajo aquí es humilde y principalmente contrastivo o corroborativo frente a estudios de mayor envergadura y calado. Sin embargo, pienso que todo/a investigador/a puede ofrecer ante cualquier realidad una perspectiva distinta, por mínima que sea, en tanto en cuanto parte de lugares diferentes en su mirada y en su observación.

He tratado de contemplar y comprender el ritual del Ramu en Meré, con todos los procesos a él asociados, como un cauce de fluido de capital social, así como una vía para fortalecer la identidad grupal y comunitaria; dicho de otro modo, una forma de producción de vínculos colectivos, tan precisos en el tipo de vida y economía tradicionales existentes en esta localidad (si bien es cierto que van perdiéndose a pasos agigantados, aunque éste no el momento para ahondar en ello).

Las reflexiones de los profesores Michael Storper o Frank Moulaert, e indiscutiblemente nombres como Robert Putnam y Alejandro Portes (elocuentes teóricos del capital social) me han ayudado en gran medida a conformar esta mirada y entender el Ramu tal y como lo describo, como justificaré en los párrafos siguientes, tratando también de realizar algunas comparaciones con casos análogos.

Ya notamos la relevancia, para la celebración de la fiesta, de algunas figuras clave: la persona que "agita" y "moviliza", la persona (o familia) que paga el Ramu, la mujer que toca el tambor, el sacerdote. Como en todo ritual, han de existir unos personajes determinados que, por motivos varios, asuman una mayor responsabilidad frente a la fiesta; a su vez, esta responsabilidad les confiere una visibilidad mayor, un protagonismo obviamente más agudo en el evento. Mecanismo similar, por otro lado, al de las economías de bienes de prestigio, donde nos hallamos con el Big Man que pone el Potlatch en funcionamiento y que, por ende, invierte y arriesga más que nadie, a cambio de lo cual recibe también mayor reconocimiento que nadie.

Estas figuras relevantes de la fiesta asumen distintas implicaciones. El sacerdote, como comenté más arriba, posee una significación especial por el puesto ritual que desempeña, con independencia de sus características personales y de su mayor o menor inclinación a la fiesta. Asimismo, y en consonancia con

\footnotetext{
${ }^{6}$ Del Campo Santos, 1997: 61, 69, 162; Gómez Pellón, 1994: 359, 254-266; Asturias, de concejo a concejo: $138,140,141$.
} 
esta inexorabilidad de su cargo religioso, su figura adopta un halo de sacralidad preciso para que las funciones religiosas y la fe de la comunidad operen debidamente.

El resto de personas significativas, sin embargo, sí deben mostrar subjetivamente una actitud distinta, una inclinación especial que, de facto, les conduzca a asumir un papel relevante en el evento. Como dije, esto les lleva a adquirir un cierto mayor prestigio frente al resto, una participación más intensa (simbólica, como la de la familia que paga, o física, como la de la chica del tambor o el hombre que moviliza a la población) y, también, una responsabilidad mayor (si algo sale mal, por ejemplo).

Consideré como una de las funciones cruciales de la celebración del Ramu el fortalecimiento de la identidad grupal que significa; todo mito, todo rito, toda fiesta, todo evento que trascienda lo meramente sobrevivencial (si es que existe algún fenómeno humano que sea meramente sobrevivencial) opera a mi entender como un avivamiento de la cohesión comunitaria y la identificación grupal, fundamentales para el desarrollo de cualquier sociedad. El hecho de que sean éstos eventos que han de hacerse conjuntamente, en convivencia, y de que impliquen una historia y unos símbolos comunes, conforma este esquema funcional del que hablo.

En el ritual del Ramu hallamos cumplidas todas estas dinámicas a las que me refiero. El origen de la celebración se "pierde" en la memoria de los lugareños, como corresponde a todo esquema mítico si seguimos a Mircea Eliade. Todos los miembros de la comunidad, por otro lado, tienen la posibilidad de participar, es decir, tienen cabida: tanto las mujeres (de cualquier edad, aunque preferentemente las niñas y las mujeres jóvenes) como los hombres pueden desfilar vestidos de aldeanas y porruanos, y cualquier habitante de la zona que se precie deseará hacerlo (hoy especialmente las mujeres).

Como pude observar, esta actitud es inculcada a los niños y niñas desde que son muy pequeños y, ante mis preguntas sobre la cuestión, todas las muchachas y ancianas respondían invariablemente que siempre y todas han querido vestirse de aldeanas. El fenómeno, pues, es generalizado, y responde a mi entender a esa necesidad de todo ser humano de pertenecer, de formar parte de algún grupo mayor donde pueda adquirir alguna significación, alguna identidad concretas.

Las funciones de sociabilidad que desempeña el Ramu son igualmente obvias; el hecho de que toda la comunidad confluya (no sólo el día de la ceremonia sino desde la formación de la comisión de fiestas) para poner en marcha un proyecto común, y un proyecto hermoso y divertido, solidifica y fluidifica sin duda los lazos grupales, armoniza las relaciones y cumple lo que el sermón del sacerdote, como se indicó más arriba, procuraba.

En una localidad donde mi breve experiencia me ha mostrado una religiosidad bastante lozana, el rol del sacerdote u hombre santo resulta crucial; con más o menos atención, los feligreses atendieron al sermón que el actual sacerdote de Meré pronunció y que, como dije, poseyó una clara intención de cohesión grupal. Se me informó de que esta persona no lleva más de dos años, a lo sumo, en la parroquia de la zona $^{7}$, lo cual corrobora la hipótesis de que no son las características personales las que imprimen relevancia sino la condición sagrada de esta persona, investida mediante la ordenación católica que es secundada por la creencia de la comunidad.

El hecho de que la fiesta posea un carácter intrínsecamente religioso (aunque mixture, como se ha registrado además en bibliografías variadas, lo sacro con lo profano en su realización, y desde luego lo

${ }^{7}$ Hubo un intento de entrevista con él; contactamos por teléfono, pero él adujo conocer apenas nada de todo aquello, por su escasa antigüedad en la zona. 
lúdico) no es cuestión baladí sino que le otorga, a mi entender, un valor trascendente de lo cotidiano o vulgar, o incluso trascendente de cualquier otro tipo de diversión o proyecto comunitarios. Ninguna fiesta que no estuviera revestida del hálito de "lo sacro" (sea lo que sea "lo sacro" en cada lugar), que no asumiera esta legitimidad cuasi-sobrenatural, adquiría igual importancia para las gentes autóctonas. Sin embargo, y como vengo indicando, pienso que las funciones sociales que desempeña esta celebración en este caso concreto son obvias.

Asimismo resulta clave, dentro del esquema mítico-religioso que subyace al evento del Ramu, la función petitoria y de salvaguarda de la comunidad que significa la ofrenda, no sólo para la familia que paga sino para todo el colectivo (véanse las letras de los cantos). Dicho de otro modo, podemos entender que la ceremonia de ofrenda aporta seguridad a la comunidad de Meré, ya que contenta y glorifica a la divinidad; se activa, pues, un mecanismo de confianza colectiva y sentimiento de bienestar análogo al de tantas otras culturas locales cuando loan, mediante diversos rituales, a sus deidades. Desde que podemos recordar, sociedades tan variadas como las celtas antiguas, las griegas, las romanas, las africanas o, naturalmente, las judeocristianas han ofrecido diversos tipos de sacrificios mediante distintos rituales, sustentados por mitos variados.

Las mencionadas son algunas de las reflexiones antropológicas que mi experiencia etnográfica en torno al Ramu de Meré me ha suscitado; sin embargo, pienso como dije que todo fenómeno humano resulta polisémico, poliédrico incluso, tanto nunca podrá ser dicha una última palabra sobre él. Estos pliegos no constituye nada más, pues, que un estudio de vocación tentativa, tremendamente escolar y dudoso, siempre revisable como acaso sea, a fin de cuentas, toda forma de antropología.

\section{Apéndices Documentales}

\section{Breve muestra del diario de campo}

[Sobre la entrevista desarrollada con el informante don Fernando, el 13 de Julio de 2004]. Entramos en aquel caserón vetusto, soberbio y hermoso, y tuve la sensación de haber traspasado también otro tiempo. Olía a húmedo, rancio, un olor que me encanta. El señor con el que iba a hablar había terminado de comer, él solo, en la cabecera de una larga mesa de madera oscura. Un mantel doblado ocupaba solamente ese espacio que él había necesitado; sobre la mesa, restos de comida, migas, y los brazos de este hombre, sus manos antiguas (lo primero que divisé) y el olor intenso de un cigarro puro. Soledad, solemnidad, silencio y eco rasgados por las voces elevadas de algunas mujeres.

Se levantó para estrecharnos la mano, un apretón bastante suave que yo he identificado, inevitablemente, con la complaciente delicadeza arcaica de este hombre para con una mujer. Es decir, habría apretado más fuerte a un hombre.

Me hacen pasar frente a la chimenea. Es verano, julio, y aunque aquí en Asturias el clima no es precisamente mediterráneo, naturalmente el fuego está apagado. Sin embargo después de comer el señor se sienta indefectiblemente en $s u$ sillón a un lado de la chimenea, con un periódico sito en uno de los brazos de aquel, y se termina su puro. Bueno, se termina... un puro es casi inagotable, así que lo chupa y lo pincha tranquilamente, sin prisas, como en una descuidada labor, mientras me habla, me escucha (poco) ofreciéndome su oreja sorda y abre y entrecierra sus ojillos viejos e inteligentes, dependiendo del momento de la conversación. Me ofrece sentarme, casi con majestuosidad, en el sillón frente a él.

Le saco poco de la fiesta. Trato, medio gritando, de presentarme y preguntarle por Meré y por la fiesta. El me escucha con dificultad, me hace algún comentario superficial acerca del Ramu y vuelve al ataque, hablando sobre mil y un temas distintos. Se nota que no tiene especiales ganas de hablar del Ramu y sí de muchas otras cosas, como sus viajes, sus tumbos, sus andares por Granada (terreno conocido para ambos y medio-hogar de los dos), sus intentos de escribir 
sobre un atardecer en la Alcazaba (intentos frustrados por un pre-plagio llevado a cabo por Federico García Lorca muchos años antes). Un largo etcétera.

Es un personaje sin desperdicio; se nota que está acostumbrado a mandar, a impresionar, a conducir, sin concesiones, y lo demuestra con el orgullo más elegante. Desde el primer momento le escucho algunos términos y expresiones cuasi poéticos, como "simbiosado" (que por cierto tal vez sea un neologismo suyo, osada iniciativa lingüística que aplaudo) o comparaciones de algunas sierras o culturas con la femineidad. Su trato para conmigo, como era de esperar, es a medias entre el de un abuelo-profesor que alecciona y a medias, a ratos, difícilmente entreverado, el de un hombre que se dirige a una mujer en edad núbil, por así decir (creo que esto sucede especialmente cuando deja de verme como una chica tonta y comenzamos a hablar de algunos poetas y de un bar-milonga de Granada, La Tertulia, donde se baila tango; acabamos casi por concretar una cita allí).

El viejo es cínicamente inteligente, a ratos. "Los ricos siempre han explotado", afirma, "lástima que a mí me tocó estar en su bando". Constituye, a mi entender, un personaje de otra época; llama al África subsahariana "el África tenebrosa" y dice de las mujeres que "como lo ensuciáis todo, antes en el Ramu no se podían poner en el altar, ahora cualquier día hasta os ponéis a dar misa". Pero, junto a todo esto (que no deja de poseer cierto añejo encanto), descubro a un hombre inteligente y sensible, consciente de muchas cosas, y que me dice que "todo el mundo es bello" cuando hablamos de la tierra y de viajes.

Llama la atención cómo interactúa con la gente del pueblo, incluida la chica que tiene empleada en su "palacio"; y en eso también se comporta como un señor antiguo de otra época, de ésa en la que la palabra "honor" aún no se había democratizado, transformándose en la de "dignidad". A él hay que llamarle "don" Fernando, tratarle de usted y no mirarle mucho a los ojos. Él mezcla generosidad, un rudo cariño y una actitud campechana con ese aire de superioridad casi intangible que parece llevar pegado a los huesos, enganchado en el alma. Repito, no tiene desperdicio.

\section{Copia de la letra de los cantares del Ramu 2004}

\section{SALIDA DE CASA}

HOY ES EL DÍA MAS DICHOSO

ESPERADO CON ANHELO

PARA LLEVAR ESTE RAMO

AL DIVINO SACRAMENTO.

DISPAREN LOS VOLADORES

NO GASTEN ECONOMÍA

PUES TODO EL MUNDO QUEREMOS

QUE LUZCA MUCHO EL DÍA.

LEVANTEN MOZOS EL RAMO

CON ALEGRÍA Y FERVOR

QUE LO VAMOS A LLEVAR

A LA CASA DEL SEÑOR.

DIRIGIMOS NUESTROS PASOS

AL TEMPLO CON ALEGRÍA

QUE UN ÁNGEL BAJE DEL CIELO

PARA SERVIRNOS DE GUÍA.

\section{LLEGADA A LA IGLESIA}

HEMOS LLEGADO A LA IGLESIA

CON ALEGRÍA Y CONTENTO 
PARA OFRECER ESTE RAMO

AL DIVINO SACRAMENTO.

AL PÁRROCO DE ESTE PUEBLO

LOS BUENOS DÍAS LE DAMOS

Y AL TODOS ESTOS AMIGOS

QUE HAN VENIDO A VISITARNOS.

SANTÍSIMO SACRAMENTO

EN OLVIDO NO TE ECHAMOS

LOS VECINOS DE MERÉ

HUMILDES TE SALUDAMOS.

ESTE PUEBLO TE REGALA

ESTE RAMO QUE TRAEMOS

RECIBELO CON AMOR

QUE DE GRATITUD VA LLENO.

VAN A CELEBRAR LA MISA

LOS MINISTROS DE LA IGLESIA

AQUÍ TIENES TUS DEVOTOS

HUMILDES EN TU PRESENCIA.

\section{DESPUES DE LA MISA}

UNA PALOMA DIVINA

DEL CIELO SE VIO BAJAR

PARA RECOGER LA MISA

QUE ACABAN DE CELEBRAR.

SANTÍSIMO SACRAMENTO

RECIBE CON GRAN AMOR

ESTE SANTO SACRIFICIO

QUE EN TU HONOR SE CELEBRÓ.

PARA HACERTE UNA CORONA YO QUISIERA RECOGER

TODAS LAS FLORES DEL CAMPO

Y EL SOL DEL AMANECER

UNA LLUVIA CELESTIAL DE GRACIAS Y BENDICIONES

VAS DERRAMANDO A TU PASO

EN TODOS LOS CORAZONES.

PUES TU DIVINA BONDAD

A TODAS PARTES ALCANZA

TODO LO PUEDE LOGRAR

QUIEN TIENE FE Y ESPERANZA.

ERES MANJAR DELICIOSO

ALIMENTO DE LAS ALMAS

LA BENDICIÓN TE PEDIMOS

ESTE PUEBLO QUE TE AMA. 


\begin{abstract}
A NUESTRO VECINO ENRIQUE EN ESTE DÍA RECORDAMOS Y PEDIMOS QUE LO ACOJAS EN TU DIVINA MORADA.
\end{abstract}

TAMBIÉN TE ROGAMOS HOY POR LOS QUE AUSENTES ESTÁN Y SUPLICAMOS SEÑOR NOS VUELVAN A VISITAR.

AUNQUE SE ALEJEN DE ESPAÑA LLEVAN CON ELLOS TU AMOR

TU NOMBRE LLEVAN GRAVADO DENTRO DE SU CORAZÓN.

ESTOS TUS FIELES DEVOTOS TE PEDÍAN MUY DE VERAS QUE LOS DEJARAS VOLVER A ESTA SU QUERIDA TIERRA.

TE HACEMOS LA REVERENCIA EN ESTE LUGAR SAGRADO Y ANTE ESTE DIVINO ALTAR DE RODILLAS NOS POSTRAMOS.

DE RODILLAS A TUS PLANTAS TE RUEGAN LOS CORAZONES QUE PROTEJAS A TUS HIJOS COMO EN EL CAMPO LAS FLORES.

NOS VAMOS A LEVANTAR CON TU SANTA PROTECCIÓN $\mathrm{OH}_{i}$ DIVINO SACRAMENTO ÉCHANOS LA BENDICIÓN.

TU PROTECCIÓN PODEROSA NOS ALCANZA NOCHE Y DÍA TODOS JUNTOS A UNA VOZ TE DAMOS LA DESPEDIDA.

\title{
REMATE
}

LLEGAMOS CON ILUSIÓN A ESTE SITIO ACOSTUMBRADO DONDE SE CELEBRA EL BAILE Y SE REMATAN LOS RAMOS.
A TODOS LOS ASISTENTES PEDIMOS ANIMACIÓN PARA REMATAR EL RAMO Y CELEBRAR LA FUNCIÓN.

VAN A REMATAR EL RAMO 


\author{
TERMINAMOS LA MISIÓN \\ GRACIAS LES DAMOS A TODOS \\ Y AL ALTÍSIMO SEÑOR.
}

\title{
Referencias Bibliográficas
}

Asturias: de concejo a concejo (LLanes y Rabadedeva). Editado por el Real Instituto de Estudios Asturianos en 1993 (carece de autor/es personal/es).

BLANCO PIÑÁN, SALVADOR. 1996. Meré, paraíso olvidado (estudios lingüísticos y poemas). Llanes: Temas LLanes $\mathrm{n}^{\circ} 76$.

DEKKER, Paul; USLANER, Eric M. 2001. Social capital and participation in everyday life. London, Routledge.

DEL CAMPO SANTOS, TERESA. 1997. Usos y costumbres en las ceremonias de los bandos en Llanes. Llanes: El Oriente de Asturias.

GÓMEZ PELLÓN, ELOY. 1994. Vida tradicional y proceso de cambio en un valle del oriente de Asturias (estudio antropológico del valle de Ardisana). Gijón: Principado de Asturias.

KEARNEY, Michael. 1986. "From the invisible hand to visible feet: anthropological studies of migration and development". Annual Review Anthropological, 15: 331- 61.

Llanes, siglo XX. 2000. Editado por El Oriente de Asturias en Llanes (proyecto dirigido por Manuel Maya Conde).

MOULAERT, FRANK. 2004. "Innovación social y desarrollo territorial: nuevas agencias públicas y privadas". Conferencia pronunciada en el seminario "Ciudades-región globales. El nuevo papel de las autoridades urbanas y regionales en la gestión de las políticas públicas", celebrado en Donostia-San Sebatián, 1 y 2 de julio.

PICCHIO, Antonella. 1999. "Visibilidad analítica y política del trabajo de reproducción social". En CARRASCO, Cristina (ed.), Mujeres y economía. Nuevas perspectivas para viejos y nuevos problemas. Barcelona. Icaria and Antrazyt.

PORTES, Alejandro. 1995. En torno a la informalidad: ensayos sobre teoría y medición de la economía no regulada. México, Miguel Ángel Porrua Grupo Editorial.

PORTES, Alejandro. 2000. "Social capital: its origins and applications in modern sociology", en Eric L. LESSER (ed.): Knowledge and social capital: foundations and applications; Butterworth Heinemann, Woburn (E.E.U.U.).

RIST, Gilbert. 2000. "La cultura y el capital social: ¿cómplices o víctimas del “desarrollo”?”, en Bernardo KLIKSBERG y Liliano TOMASSINI (comp.): Capital social y cultura; claves estratégicas para el desarrollo. Banco Iberoamericano de Desarrollo, Fundación Felipe Herrera, Universidad de Maryland y Fondo de Cultura Económica, México D.F.

de SOUSA SANTOS, Boaventura. 2003. Crítica de la razón indolente. Contra el desperdicio de la experiencia. Bilbao, Desclée, Palimpsesto.

STORPER, MICHAEL. 2004. "Sociedad, comunidad y desarrollo económico". Conferencia pronunciada en el seminario "Ciudades-región globales. El nuevo papel de las autoridades urbanas y regionales en la gestión de las políticas públicas", celebrado en Donostia-San Sebatián, 1 y 2 de julio.

YÚDICE, George. 2002. El recurso de la cultura [Usos de la cultura en la era global]. Barcelona, Editorial Gedisa.

\section{Otros documentos alternativos consultados}

Guía turística "Oriente de Asturias". Comisión de festejos "La Blanca", Nueva de Llanes, 2001. Documentos periodísticos de "La voz de Asturias" (recortes del mes de septiembre de 2001). 
Enciclopedia de la "Asturias popular" 18: "De la tecnología agraria preindustrial”. Editado por el periódico "La voz de Asturias".

Folletos de las fiestas de San Cosme (Cangas de Onís) pertenecientes a los años 2000, 2001 y 2003.

Fascículo- publicación sobre el valle de Ardisana por parte del "Grupo Ardisana", Oviedo, 1987. 